\title{
Old Romanian Iconographers and Their Icons on Glass: Materials, Techniques, and Secrets

\author{
Mihaela D. Leonida
}

\section{Fairleigh Dickinson University University, Teaneck, NJ 07666, USA. mleonida@fdu.edu}

\begin{abstract}
Peasant icons offer the strange image of a folk art, clearly outlined and unique in its technical quality and sensitivity. They are the result of the harmonious merging of moralizing teachings and the mythology of an ancient faith, of subjects taken from the Romanian folklore, from apocryphal books, and the precepts of a local ethical code, thousands of years old. The slight emotional emphasis therein is on the national and social context of a people with a stormy and too frequently changing history. The study introduces the Romanian icons on glass in the cultural environment of Central and Eastern Europe making comparative notes and historic connections. Less known information about how the peasant iconographers prepared their own materials and the technical skills they mastered in creating these icons is presented together with examples of icons from different geographical areas of today's Romania.
\end{abstract}

\section{Introduction}

Peasant icons on glass are a unique form of folk art both in technical quality and sensitivity. While a few paintings on glass were found in Central Europe (mainly Bohemia and Austria), the area where this type of craft was practiced extensively and reached maturity was Transylvania and Northern Moldova. It is not clear when this art appear in the Romanian area. Because of the frailty of the glass support, and of the poor adherence of colors to this shiny, nonporous surface, not too many ancient icons on glass reached us. Icons found in different collections, which bear an indication that makes it possible to date them (Figure 1), belong usually to the second half of the eighteenth century [1]. In the Romanian area this genre reached its pinnacle during 1830-1900. After 1900 this technique was used by very few iconographers [2].

Some researchers consider that this form of art, painting sacred figures on the back of a glass plate, came to the Romanian area from Central Europe $[3,4]$. In support of this hypothesis, it is worth mentioning that in Transylvania most of the names of the colors, pigments and other materials used by the peasant painters have a Germanic resonance. However, this may also indicate the source of materials since the themes and models used are designated by pure Romanian terms.

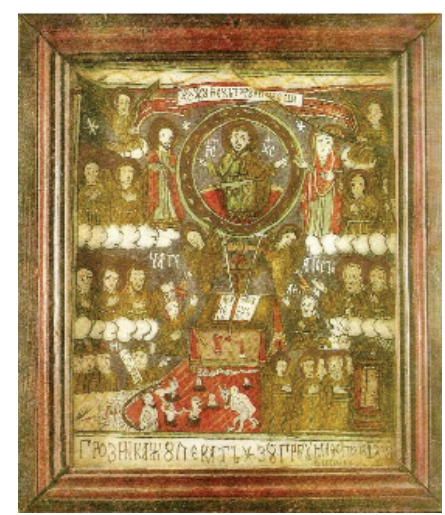

Figure 1. Icon on glass, dated 1838 and signed Matei Popa

According to the principles of iconography, the themes and their frequency as well as the characteristics of the details do not point to a Germanic model but to a Romanian, Byzantine or Near Eastern one. The chromatics and the 
often used golden background remind us of Byzantium where painting on glass was already known several centuries earlier [3]. There is still an unanswered question. If this form of art came to Romania from Central Europe, why cohabiting ethnicities in Transylvania, of the same Catholic faith as the peoples of Central Europe, did not adopt it?

Well-known centers for painting on glass developed in Transylvania, whereas those in other regions were few and much less studied. The products of the various centers bear certain local characteristics that can be easily detected [5]. In the Olt Country (center in Southern Transylvania) two different currents were detected: one represented by the icons made by skilled iconographers and another one represented by much less educated craftsmen [6]. This is not surprising since long before the art of painting on glass developed in the Romanian area, iconographers had lived and worked there using other techniques. The iconographic recommendations of the hermeneias and the imprint of those who painted on wood are easy to see in the icons painted on glass.

The icons were transported by carts belonging to the iconographers themselves, to peddlers, or were carried by shepherds during the seasonal migrations of flocks from one pasture to another. Icons painted on glass spread throughout all the Romanian provinces, often far away from the centers where they were made. Icons were purchased as presents for different occasions or for a girl's dowry because, in certain regions, no girl could marry without owning an icon. Icons representing the Virgin (Figure 2) or the Nativity were especially popular since they were considered symbols of fecundity.

While the iconographic aspects of the icons on glass were studied by many researchers, little has been written about the skill and technical ability of those who painted them.
This study focuses on the material face of the icons on glass: the raw materials and the materials used to make them, on preparatory technologies, and on the techniques used by the Romanian iconographers who used glass as the support of the pictorial layer. The information comes from the secretive painter's manuals and from interviewing old iconographers who were still active during the last decades of the twentieth century.

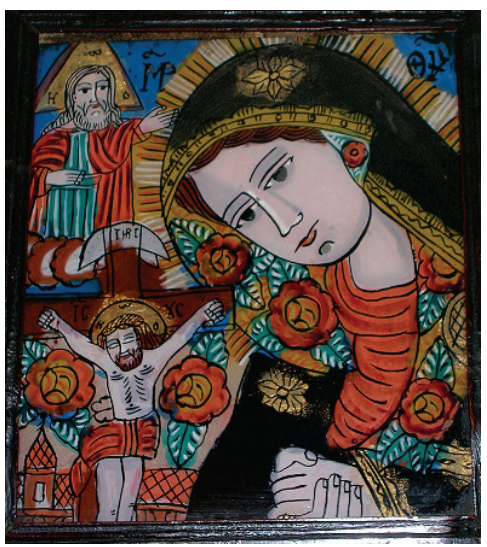

Figure 2. Our Lady of Sorrows (orivate collection)

\section{The Cast and the Time}

In a peasant iconographer's workshop family provided help, as happened in other techniques of painting practiced in that area [7]. The steps that required no artistic gift or technical skills (grinding and sifting of the pigments, their "rubbing" in a mortar with a pestle, preparation of adhesives, dye stuffs, additives and binding materials, and making the frames) were carried out by members of the family with less experience. The coloring and the application of the local hues were carried out by more skilled members of the family. Still more qualified ones would make the drawing, the writing, and put in the patches of light. As a rule, retouching - almost impossible in this technique - and the application of the gold leaf were done only 
by the head of the workshop. In busy workshops colors were applied concomitantly on several icons, to save both materials and time.

The peasant iconographers painted mostly during the cold season, when work in the fields and shepherding slowed down. The icons were sold at fairs or by peddling, for money or exchanged for cereals or wares from the homestead of the buyer. Often this trade took place also during winter when peasants and shepherds stayed home and many weddings were celebrated [8].

\section{The Materials}

Glass for the support was of the sodalime type and it protected the painted layer like varnish does on easel painting. It was obtained from small factories (glăjării) existing, as a rule, in forested zones, due to the large volume of wood needed for furnaces. Glass was also supplied by local merchants, by hawkers or by pilgrims coming to monasteries on the patron saint's day [8]. The glass was cut into small pieces of various sizes for easier transportation. The size of the glass sheets was variable in different centers or even in the same center during different periods of time. In centers like Nicula (in the midst of a poor, less developed area) the icons were smaller than in the affluent center Scheii Braşovului, since the price of glass weighed heavily in the cost of the completed icon. No icons were painted on mirror glass in this geographical area.

The technological process for glass making was a rudimentary one. A mixture of quartz sand (silica as main ingredient), soda ash, limestone, and, sometimes, cullet (for furnace efficiency) was melted and then blown into cylinder-like shapes, the thickness of the wall being approximately the same as that of the future glass sheets. This thickness was not the same throughout the cylinder or throughout the glass sheet obtained when the cylinder was split lengthwise along a generating line and "stamped" down on slabs of smooth chamotte bricks, previously heated in special ovens. As neither the melted nor the "stamped" glass could be maintained at the required optimal temperatures, gas bubbles of various sizes remained within the glass. Inner stress lines also appeared on cooling due to an uneven temperature within the sheet, increasing its brittleness. When, long after the icon was completed and framed, the glass sometimes broke without any apparent cause, probably due to accidental mechanical stress (vibrations, mechanical shock, uneven dilation) and when these accidents occurred in connection with certain significant family events, they acquired a miraculous connotation.

As a consequence of the rudimentary processing of the glass, its surface remained slightly undulated, having been cooled too much and too fast before being "stamped" down. These undulations can be detected with the finger tip. The effect of these imperfections was not always unpleasant. The differences in the thickness of the glass, the undulations and air bubbles embedded in the material and the fact that the colors are seen through the glass impart, owing to complex optical phenomena, depth to the hues and result in vibrant colors. When, towards the end of the 19th century, glass from commercial sources was exclusively used, without any of the defects mentioned, and when the Romanian folk painting on glass showed the first signs of decline, the charm of this kind of folk art was lost.

\section{The Drawing and the Models}

To ensure good adherence of the colors, fat was removed from the glass using lye wash, then rinsing with water and drying before painting. Lye wash was prepared either in large vessels or in the hollowed trunk of a hard wood tree by scalding ash.

In painting on glass the drawing was usually copied using a model, an engraving, a xylograph, or an illustration from a religious book and was drawn in pencil, ink, China ink, black or red 
tempera. Some artisans drew from imagination or from the details of several models or engravings so as to create a composition of their own. When doing so, or even when using models, the iconographers would introduce or eliminate elements, trying to make each icon unique and thereby imprinting their own skill and feelings. In some peasant icons on glass perspective was totally ignored giving them a unique, primitive charm. When models were made, they were borrowed, copied, restored, refreshed, and inherited. They were lost by wear or by accident (fire, flood, invasion, vandalism) so that few still exist nowadays.

\section{The Pigments and the Colors}

The pigments used in painting icons on glass were obtained from other iconographers' workshops, prepared in the artisan's workshop, or bought from merchants and peddlers.

Raw materials from natural sources (iron salts, manganese and copper hydroxides and oxides, cinnabar, kaolin, chalk) were processed (cleaned, ground, sieved and washed) in the peasant workshops. From the hermeneias and Romanian miscellanea it can be seen that, in that area, several preparative technologies (for white lime, white lead, cinnabar, green copper acetate) used in other parts of the world were known and practiced with local innovations [7].

Certain organic dyes obtained from plants (by infusion or extraction) were used in addition to the inorganic pigments as well. These dyes were fated, by their very composition, to a more or less rapid decomposition under the sunlight which was not stopped by either the glass or the superposition of colors. These, however, offered some protection from the attack of the environmental agents to which icons were exposed. Sometimes this attack was strong enough for the dyes to disappear completely. The chalky, earthy or even faded colors in some older icons, when not caused by the use of certain pigments of questionable quality, represent what is left from parts colored only using dyes whereas others, painted only using inorganic pigments, maintained a fresh hue and shine.

The black pigment used in painting on glass by the Romanian icon painters was prepared from carbon black obtained by the incomplete combustion of certain indigenous resins, of bones, oak or linden wood, grapevine stems, peach stones, or walnut shells followed by thoroughly grinding the resulting charcoal. The pigment obtained from grapevine stems resulted in a cold grey color of particular beauty characteristic for painters of yore from this area.

Unequally used, the few white pigments had a fairly varied composition (fine chalk or kaolin powder, ceruse and - starting from the second half of the nineteenth century - zinc oxide). The white pigments obtained from kaolin or chalk were prepared from the raw material found in natural deposits by breaking down, washing, drying and sifting. White lead (ceruse) was bought, obtained from other painters or prepared in the workshop by letting vapors of acetic acid (from concentrated vinegar prepared in the household) act on lead ore for about 40 days in the presence of carbon dioxide produced by the anaerobic fermentation of horse dung [7]. While these pigments were seldom bought, zinc oxide was always purchased from traders.

The red pigments were cinnabar (vermilion), minium (lead tetroxide), ferric trioxide, and, starting in the nineteenth century, fuchsia red. These were all provided by traders with the exception of cinnabar. This last pigment was obtained from natural local deposits and was also produced in some of the iconographers' workshops following recipes found in the Romanian painter's manuals. This procedure was the same as the one used in medieval Europe, at Mount Athos, or in China two thousand years earlier [8]. 
Contamination with minium (of higher density and cheaper than cinnabar), a fraudulent trick, was far less harmful in painting on glass than in easel or mural painting (owing to the protection of the glass and overlay of other colors and of gold leaf).

Ferric trioxide, a dark red pigment, was obtained from ochre by calcination or directly from natural deposits. The tint differed according to the ore it was extracted from, its purity, and the temperature and duration of calcination. The higher the temperature and the longer the duration, the darker the red due to the higher proportion of magnetite $\left(\mathrm{Fe}_{3} \mathrm{O}_{4}\right)$. Iconographers used sometimes a mixture of hematite and goethite to replace cinnabar (expensive) [9].

Yellow pigments were obtained from natural deposits or bought. However a yellow, as yet unidentified, plant extract was also used [10]. The ochre tint varied depending on the proportion of aluminum silicates in the ore, which would sometimes vary even within the same deposit. Ochres were particularly interesting for painting on glass because of their high opacity and covering capability. The imported Thassos ochre had a redder tint owing to its higher content of iron trioxide .

The green pigment used was copper acetate, prepared, as in Western Europe or at Mount Athos, in closed containers where acetic acid vapors (from concentrated vinegar) reacted with small pieces of copper.

Brown and purple pigments were manganese compounds obtained from natural deposits or from commercial sources. Azurite, $\mathrm{Cu}_{3}\left(\mathrm{CO}_{3}\right)_{2}(\mathrm{OH})_{2}$, and ultramarine, the former from natural sources and both from commercial sources, were used as blue pigments. Later on they were replaced by cobalt blue and ceruleum, both commercially available.

Gold pigment, primarily used from the middle of the 18th to the end of the 19th century for aureoles, stars and sometimes for the background, was prepared from imported bronze powder or gold leaf available commercially or from other workshops [5,10]. The use of gold is unanimously considered to be the influence of Byzantium. The bronze powder was increasingly used after oil colors started to be used. While in some icon centers (Braşov) it was little used, in some others (Nicula) only seldom, in Laz-Sebeş it was overused. In older icons, in the simpler ones, and even in the entire work of some iconographers ochre was used instead (less expensive).

Starting with the middle of the 19th century, in some icon centers (The Olt Country, Laz-Sebeş) the background of the icons on glass was no longer painted. Instead, metalized paper or tin foil was applied on the back of the painting. The colors did not adhere well to it and the painted layer soon began to peel off. The outlines however resisted better since the colors used to draw them were prepared with a stronger binder.

At first, icons on glass were painted with tempera colors and the influence of painting on wood panels was obvious. The colors were prepared by "rubbing" the pigments with a pestle in rudimentary mortars made of hard stone together with an emulsion of animal glue (from sheep skin or rabbit bones), egg yolk, and small amounts of ox gall and vinegar. Vinegar was added to the binders both as a coagulant and preservative of the colors against biodegradation.

Analysis of the layers painted in tempera in the early days is almost impossible today since most of them were subsequently restored using oil colors. Later on, at times that varied from one center to another, oil paints started to be used. They were prepared by "rubbing" the pigments with linseed oil. Ceruse was the only one which was "rubbed" with walnut oil because it is itself a pretty strong siccative. With the other colors a colorless siccative was added after "rubbing". 


\section{The Technique}

The technique of painting on glass was very simple and it was the same throughout the entire Romanian area. Four main difficulties were encountered in painting on glass. First, because the painting was done in a reversed position, the side painted on became the back of the icon and the order of the colored layers was reversed, thus making it fundamentally different from any other technique. A second difficulty was the virtual impossibility to retouch. Thirdly, colors have a poor adherence to glass, and lastly a big problem is the fact that icons on glass cannot be restored when necessary as easily as those painted on wood or those painted in the secco technique on dry plaster.

The outlines were traced with black pigment introduced in a mixture of linseed oil, turpentine and a little lead acetate (a colorless siccative to ensure quick drying). Less often the drawing was done with a dilute emulsion of egg yolk in which carbon black was suspended. In certain centers (Nicula and Banat), some of the painters drew the outlines in black and other lines in red, especially the contour and features of the face, hands or uncovered parts of the body, as in fresco painting [11].

Many iconographers could not write. That is why the writing on some icons is drawn in a decorative motif. After many and repeated copies of a model, the letters and the words copied by artisans who could not read themselves had no longer any meaning.

The frames of the Romanian icons painted on glass were made using different wood essences, with or without a profile, painted, colored or stained with tanner's drench. The wood most used was fir but maple, plum tree, oak and walnut were used as well. The frames were sometimes made by the artisan himself or by the village carpenter. The icon was transported after having been framed as the painting readily came off. The back of the frame was covered with thin wood boards that both protected the icon and rendered the frame more rigid. In the Nicula center cherry tree bark was also used to cover the back of smaller icons [3]. The papers put between the painting and the back for increased protection often offered interesting indications regarding the age of the icon, or about certain techniques used, or were even of historical or social interest.

Until the end of the 19th century the frame was assembled with wooden pegs and later on with metal nails. In some cases the framework was joined together by wooden tenons, which increased its rigidity and stability.

Painting on glass originated elsewhere, but the Romanian peasant iconographers made it their own and brought this art genre to heights unknown before or since. The originality and unitary style of Romanian icons on glass are impressive and the craft and technical knowledge which make their hidden face are no less so.

\section{Acknowledgment}

To Mihail Mihalcu, the trail blazer.

\section{References}

3) Wendt, H.C., Rumänische Ikonenmalerei. Eine kunstgeschichtliche Darstellung, Erich Röth Verlag, Eisenach, 1953.

4) Ioanidu, I.C., Radulescu, G.G. Bulletin of the Commission for Historical Monuments, (1942), 113.

5) Dancu, I. Dancu, D. Peasant painting on glass, Editura de Stat pentru Literatura si Arta, Bucharest, 1975.

6) Iorga, N. Les arts mineurs en Roumanie, vol. I. Édition de L'Imprimerie de L'État, Bucharest, 1934.

7) Mihalcu, M., Leonida, M.D. Din tainele iconarilor romani de altadata, Ed. Eikon, Cluj-Napoca, 2009.

8) Mureşanu, A. Reflexii (Restituiri), Ed. Dacia, Cluj-Napoca, 1977.

9) Mihalcu,M. Romanian medieval values, Ed. Sport-Turism, Bucharest, 1984.

10) Irimie, C., Focsa, M. Romanian icons painted on glass, Ed. Meridiane, Bucharest, 1969.

11) Mihalcu, M., Leonida, M.D., Bul Fiz Chim, (1981) 5, 242.

12) Popescu, A.I., Arta icoanelor pe sticla de la Nicula. Ed. Meridiane, Bucharest, 1969.

13) Leonida, M.D., The materials and craft of early iconographers, Springer Verlag, Heidelberg/New York/London, 2014 